\title{
XXVII. On minium
}

\section{Richard Phillips F.R.S.}

To cite this article: Richard Phillips F.R.S. (1833) XXVII. On minium, Philosophical Magazine Series 3, 3:14, 125-129, DOI: 10.1080/14786443308648141

To link to this article: http://dx.doi.org/10.1080/14786443308648141

册 Published online: 01 Jun 2009.

Submit your article to this journal $2 \pi$

III Article views: 2

Q View related articles $₫$ 
There appear to me only two ways of accounting for this curious fact. We must either suppose that the electricity having been first arranged in a particular direction is afterwards more easily arranged in trials in the same direction than in the contrary:-or, that in reversing the poles we do not destroy the whole of the magnetism formerly induced, but actually arrange a new series of atoms in an opposite direction; so that when the magnet has lost all its power, it has done so, simply because we have two equal magnets formed on the same piece of steel, having their poles in opposite directions.

The magnetism which has been newly induced is more easily destroyed than that which has been induced days or years ago; since by suddenly destroying the newly induced magnetism, the old, being held by a more powerful coercitive force, will regain its force when its temporary antagonist power has been removed.

As this curious fact appears to me new, and sufficiently interesting to be made known, I request you to give it a place in the Philosophical Magazine.
I am, dear Sir, yours truly,
University of London, July 18, 1833.
William Ritchie.

XXVII. On Minium. By Richard Phillips, F.R S. \&c.*

A FTER the last sitting of this Society, the President men$A$ tioned to me a paper on Minium, by M. Dumas, contained in the 49th volume of the Annales de Chimie et de Physique, dated April 183\%. In this memoir the author shows that minium is a very different compound from what it is usually supposed to be, and consequently that it is not a sesquioxide, or as it is sometimes termed, deutoxide of lead. Dr. Dalton also recalled my attention to his having previously announced the same fact in his New System of Chemical Philosophy, published in 1827 (vol. ii. p. 39).

Opinions so different from those commonly entertained, induced me to make some experiments on the subject, and an account of them may not be altogether unacceptable to this Society, tending, as they do, to confirm the views of its learned President, and proving their originality. Before I state the opinions of Dr. Dalton, or of M. Dumas, or my own experiments, it will be proper to give the generally admitted composition of the yellow or protoxide, and of the brown or per-

* Read before the Literary and Philosophical Society of Manchester, early in the present year.

$\dagger$ An abstract of M. Dumas' results will be found in Lond. \& Edinb. Phil. Mag. vol. ji. p. 402. 
oxide, of lead. Dr. Dalton in his work already alluded to, considers the protoxide as composed of 7 oxygen and 90 lead, and the peroxide of 14 oxygen and the same quantity of metal. Now as these differ but little from the atomic proportions usually adopted, I shall consider the protoxide as composed of an atom of oxygen $=8+104$ an atom of lead, and the peroxide of $16=2$ atoms oxygen +104 of lead.

It is well known that when red-lead is treated with nitric or acetic acid, it is separated into protoxide, which is dissolved, and peroxide remaining unacted upon; and Dr. Dalton correctly observes, that if minium were a sesqui-oxide, it ought to leave more than 50 per cent. of peroxide when acted upon by either of the above-named acids; the sample, however, which he examined left only 20 per cent. of peroxide, proving that it was not a sesqui-oxide.

Dr. Dalton concludes from his experiments that " the minium of conmerce is constituted of 1 atom of oxygen, holding 6 atoms of yellow oxide together; or it is composed of 100 lead and 9.07 oxygen." And he observes, that "sohen it is digested in cold acetic acid the residuum constitutes another oxide, consisting of 1 atom oxygen and 3 of yellow oxide, or 100 lead, and $10 \cdot 4$ oxygen, possessing the same colour as the former, but distinguishable by its not being acted on by cold acetic acid, and by its containing troice as much brown oxide and extra oxygen as minium."

These experiments are, I confess, new to me, and certainly have not excited the attention which they merit; and without at present entering further into this part of the subject, I shall just state that $I$ have found acetic acid to separate a large proportion of protoxide from minium, without altering its colour at all; and consequently proving that it is not a sesqui-oxide, for if it were, the residue would become brown by the development of peroxide. If, however, the dilute acetic acid be used in excess, then this change actually occurs, at least so I found it; but this does not appear by Dr. Dalton's experiments.

M. Dumas in the paper above referred to, does not state the opinions of other chemists in detail, consequently it cannot be ascertained whether he was acquainted or not, with those of Dr. Dalton; he merely says, that previous analysts do not agree as to the nature of minium. The facts stated by M.'Dumas indeed prove the existence of several varieties of minium; and according to his experiments, which appear to have been conducted with great care, the increase of oxygen goes on very slowly from 8.26 per cent. in the product of the first calcination, to $8 \cdot 79$ contained in the minium of the eighth operation. He found also that white lead sub- 
mitted to three calcinations gave a fine orange minium, containing 9.24 per cent. of oxygen; this, however, he observes is still below the proportion required to constitute the lead a sesqui-oxide, and which, in fact, amounts to 10.38 per cent.

M. Dumas states minium of the eighth operation to consist of 74 protoxide, and 26 peroxide; that obtained by calcining white lead, of 66.8 protoxide, and 33.2 peroxide; and pure minium he considers as equivalent to $65^{\cdot} l$ of protoxide with $34 \cdot 9$ of peroxide.

I shall now state the results of my own experiments on minium; that which I used appeared to be free from carbonate of lead, and was moderately dried before submitting it to the following experiments:-Two hundred grains were digested in an ounce of strong nitric acid, diluted with half a pint of water ; 49.6 grs. of peroxide were left, consequently the minium was separated into

Protoxide of lead .......... 75.2

Peroxide of lead ........... 24:8

$100 \cdot 0$

I also boiled some of the minium with excess of moderately strong acetic acid; by this operation it was separated into



These results do not differ much; but taking the mean, we have minium resolved into

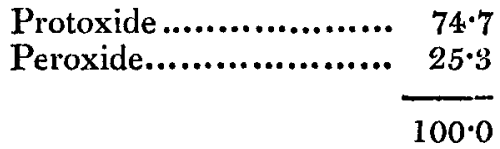

Now this result differs considerably from that obtained by Dr. Dalton; he procured only 20 per cent. of peroxide. The cause of this difference is readily explained by referring to M. Dumas's Table of Experiments; from which it appears that minium of the third calcination yields only 20.3 per cent. of peroxide; while that of the eighth gives 26 per cent. Dr. Dalton appears to have employed a specimen of the former, while I used one of the latter.

In order to determine the proportion of pure minium in the specimen which I used, I added separate portions of 200 grains each, to the annexed quantities of strong acetic acid, diluted with half a pint of water; viz. one, two, two and a half, and three drachms. I found that the minium digested in the first lost 22 per cent.; in the second 27.5 ; and in the third 
29.1 per cent.; and in all these cases the residue remained perfectly unchanged in colour : the quantity of protoxide dissolved by the fourth portion of acid I did not determine, for the residue had acquired a slight brown tint, showing that a portion of the pure minium had been decomposed. From these experiments I conclude that the maximum of protoxide had been dissolved by the acetic acid, and consequently that the specimen consisted of

$$
\begin{aligned}
& \text { Pure Minium.............. } 70 \cdot 9 \\
& \text { Protoxide................. 29.1 } \\
& 100 \cdot 0
\end{aligned}
$$

It now only remained to determine the composition of the 70.9 of pure minium. I therefore treated a portion of it with great excess of diluted nitric acid, by which it was separated into

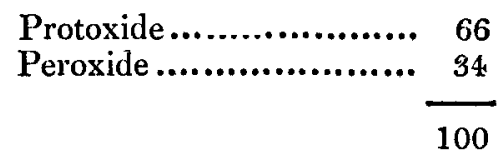

It will be observed that this determination agrees very nearly with that resulting from the action of nitric acid upon redlead. I have already stated that it gave 25.3 per cent. of peroxide, while, as will appear by a slight calculation, according to the action of nitric acid upon the pure minium, it should have yielded $24 \cdot 1$ per cent.

We may consider the constitution of minium under different points of view :- first, merely as a compound of lead and oxygen; in this case 104, an atom of lead appears to be combined with $9 \cdot 8$ of oxygen, which are proportions irreducible to any probable atomic constitution. Indeed on inspecting M. Dumas's Table of the composition of eight different kinds of red-lead, it must be admitted that this substance is a mixture of true red oxide with variable proportions of protoxide.

The next question is, What is the constitution of the true red oxide? by which $I$ mean that left unchanged by the action of dilute acetic acid upon common red-lead.

Now I have shown that this is resolvable into 66 of protoxide, and 34 of peroxide; and these results agree very closely with those of M. Dumas, who states what he calls pure minium, to be composed of 65.1 protoxide, and 34.9 peroxide, which I agree with him in considering as equivalent to two atoms of the former, and one atom of the latter, or three atoms of lead and four atoms of oxygen. And I have great pleasure in observing that these results are in perfect accordance with 
the statement of Dr. Dalton, long since published; for he mentions that the red oxide, left after the action of dilute acetic acid upon common red-lead, consists of an atom of oxygen, and three atoms of yellow oxide, which are of course equivalent to four atoms of oxygen, and three of metal.

XXVIII. Revierws, and Notices respecting New Books.

Report of the First and Second Meetings of the British Association for the Advancement of Science; at York in 1831, and at Oxford in 1832: including its Proceedings, Recommendations, and Transactions. London, 1833, 8vo, pp. 624; with an engraved Geological Section through Europe.

[Continued from vol, ii. p. 464.]

IN concluding our account of Prof. Airy's Report on the progress of Astronomy, we have to remark that he has omitted to notice certain important observations of Saturn, of recent date, the statement of which would have formed part of his sixth section. We do this in the spirit of endeavouring to render still more complete, so far as our reading enables us, his meritorious labours, and not at all in that of complaining of a single omission, in a series of details probably more copious and more comprehensive than any similar collection. The observations to which we allude are those made in 1828 by MM. Schwabe and Harding, repeated with doubtful result by Sir J. South and Sir J. Herschel, but subsequently confirmed by Struve, (all recorded in the Montbly Notices of the Astronomical Society,) which have shown that the rings are not absolutely concentric with the body of Saturn, and the theoretical importance of which (subsequently, however, to the printing of Prof. Airy's Report) has been pointed out and explained by Sir John Herschel *

Professor Airy's Report is followed by a short "Report on the Tides" by Mr. Lubbock : It commences with a brief sketch of the successive improvements which the theory of the tides has undergone, from the time when the details left open by Newton were taken up by Bernoulli, Euler, and Maclaurin, to the prize question on the general problem propused last year by the Academy of Sciences at Petersburgh. This is followed by some historical and critical remarks

* See Phil. Mag. and Annals, N.S., vol. iv. pp. 62, 136; and Sir John Herschel's volume on Astronomy in the Cabinet Cyclopædia, p. 284. It occurs to us that it would be at once interesting and useful, as much difference of opinion still exists in the scientific world, on the precise character of the relative value possessed by observation and experiment, and by mathematical investigation, respectively, if some competent anthority would reply explicitly to the following question:-Had the oscillation of the centre of gravity of the rings round that of the body of Saturn been demonstrated theoretically before it had been observed? or has the observation of the fact (previously unsuspected) produced an improvement in the theory? The fact was no soones established than the necessity of it became evident; but had it been predicted by mathematical theory, or not?

Third Series. Vol. 3. No. 14. Aug. 1833. 